\title{
PLANO DIRETOR DE GESTÃO DA INOVAÇÃO EM UMA AGÊNCIA REGULADORA DO ESTADO DE SÃO PAULO
}

Maria Regina Rocha

Mestranda em Administração do Desenvolvimento de Negócios do Centro de Ciências Sociais e Aplicadas da Universidade Presbiteriana Mackenzie (UPM). Superintendente da Agência Reguladora de Saneamento e Energia do Estado de São Paulo (Arsesp) - distribuição de gás natural. E-mail: rocha-regina@uol.com.br

\section{Marcos Antônio Franklin}

Doutor em Administração de Empresas pela Universidade Presbiteriana Mackenzie (UPM) e mestre em Qualidade pela Universidade Estadual de Campinas (Unicamp). Professor do núcleo docente permanente do Mestrado Profissional em Administração do Desenvolvimento de Negócios do Centro de Ciências

Sociais e Aplicadas da UPM. Com experiência profissional na área de gestão da inovação e processos organizacionais, desenvolve projetos de pesquisa aplicada em temas relacionados com gestão da inovação, sustentabilidade, redes, qualidade, ambiente e processos organizacionais. Tem publicações em congressos e revistas nacionais e internacionais sobre esses temas. E-mail:franklin.marcos@gmail.com 


\section{Nilton Galli Bassi}

Mestrando em Administração do Desenvolvimento de Negócios do Centro de Ciências Sociais e Aplicadas da Universidade Presbiteriana Mackenzie (UPM). Coordenador do Mackenzie Soluções. E-mail: nilton-bassi@uol.com.br

\section{Marino Kobaiashi}

Mestrando em Administração do Desenvolvimento de Negócios do Centro de Ciências Sociais e Aplicadas da Universidade Presbiteriana Mackenzie (UPM). Gerente comercial da Sulmetais Revestimentos Arquitetônicos. E-mail:marinokobayashi@uol.com.br

\section{Guilherme Eli}

Mestrando em Administração do Desenvolvimento de Negócios do Centro de Ciências Sociais e Aplicadas da Universidade Presbiteriana Mackenzie (UPM). Gerente territorial de vendas da Philip Morris International. E-mail: guilhermeely@hotmail.com

\section{RESUMO}

O presente estudo apresenta o Plano Diretor de Gestão da Inovação (PDGI) que será implementado em uma agência reguladora do estado de São Paulo visando transformá-la em uma autarquia inovadora, o que melhorará o atendimento às de- mandas oriundas de diversas áreas da sociedade. O PDGI estabelece as grandes linhas de orientação para as atividades a serem desenvolvidas na Agência Reguladora de Saneamento e Energia do Estado de São Paulo (Arsesp) durante o período de 2018 a 2021. Este documento descreve as premissas que embasaram a elaboração do mapa estratégico, representado pelo framework, que sintetiza e representa visualmente os direcionamentos estratégicos que serão estabelecidos pela Arsesp, traduzidos pela missão e visão e abrangendo diretrizes e objetivos norteadores do desempenho institucional. Por meio do modelo de gestão da inovação, será apresentado, na forma de inovação dos processos, o critério de priorização da análise das demandas. A proposta prevê que, inicialmente, o PDGI seja executado na área da diretoria do gás canalizado, servindo de base de preparação para a formação de uma atmosfera inovadora que será, posteriormente, compartilhada com as diretorias de saneamento básico e energia elétrica, sob o patrocínio e alto envolvimento da diretoria colegiada.

\section{PALAVRAS-CHAVE}

Gestão da inovação. Plano diretor. Agência reguladora. Critérios de priorização. 


\section{INTRODUÇÃO}

Com base na abordagem metodológica para trabalhos práticos e aplicados de acordo com Marcondes et al. (2017), este trabalho foi desenvolvido com o objetivo de apresentar o Plano Diretor de Gestão da Inovação (PDGI), a ser executado na Agência Reguladora de Saneamento e Energia do Estado de São Paulo (Arsesp), a partir da identificação da oportunidade de inovação incremental de processos de análise das demandas oriundas de diversas áreas da sociedade. Propõe-se a adoção de critérios de priorização para análise das demandas. O projeto será executado no período de 2018 a 2021, na diretoria do gás canalizado, e posteriormente nas demais diretorias da agência.

De acordo com Downey, Hellriegel e Slocum (1975, p. 618), "um ambiente dinâmico é aquele em que os fatores relevantes para a tomada de decisão estão em constante estado de mudança”. Lawrence e Lorsch (1967) argumentam que, com o aumento da incerteza, maiores níveis de diferenciação e de integração são exigidos em termos de segmentação de tarefas como uma forma de melhorar a agilidade e a capacidade de respostas adaptativas ao ambiente.
A Arsesp, por se tratar de uma autarquia, é regida por leis e regulamentos aplicados ao setor público, possuindo processos administrativos que tendem a ser mais burocráticos, o que dificulta a agilidade e flexibilidade de adaptação às mudanças do ambiente externo. Nesse sentido, com a incerteza dos ambientes dinâmicos, as empresas e os gestores necessitam cada vez mais de informações concisas e diferenciadas para tomar decisões mais precisas (GALBRAITH, 1973).

Considerando que os assuntos são diversos e com distintos impactos e prioridades, a metodologia de priorização a partir de critérios qualitativos mostrará o resultado do atendimento das demandas de forma objetiva, permitindo uma ampla gama de benefícios socioeconômicos e ambientais. Esse projeto de inovação trouxe, sob a ótica dos processos de análise das demandas da agência, informações mais concisas e, por consequência, mais dinamismo à tomada de decisão.

\section{Objetivo do trabalho}

Inovação e automação dos processos de análise oriundos das diversas demandas dos setores da sociedade, observando o in- 
teresse público, visando à melhoria da finalidade da agência, por meio da

- Criação de critérios dos processos para a priorização das demandas.

- Padronização e automação das demandas conforme os critérios estabelecidos.

\section{CONTEXTO E REALIDADE INVESTIGADA}

\section{Agência reguladora}

A Arsesp é uma agência multissetorial que regula, controla e fiscaliza os serviços de gás canalizado e de saneamento básico de titularidade estadual, bem como os serviços de energia elétrica ou de saneamento básico municipal, delegados ao estado por seus titulares. Administrada por uma diretoria colegiada formada por cinco membros, a Arsesp é autarquia de regime especial, com autonomia decisória, administrativa, orçamentária e financeira.

O PDGI da Arsesp será executado, especificamente, na área do gás canalizado, a qual será considerada a área-piloto. A escolha deveu-se ao forte engajamento da diretoria do gás canalizado, que busca por oportunidades de inovação. Justifica-se, ainda, devido à importância do setor para o estado de São Paulo, que vem incentivando o gás natural como o insumo de transição para as energias renováveis e garantia da segurança energética.

O estado de São Paulo é o maior consumidor nacional de gás natural, utilizando anualmente cerca de 5 bilhões de metros cúbicos, e a indústria paulista consome mais de $80 \%$ desse valor. Apesar de ser um combustível fóssil, o gás natural é uma alternativa ambientalmente vantajosa em comparação ao óleo combustível, reduzindo a emissão de gases de efeito estufa.

O estado está dividido em três áreas de concessão de distribuição de gás canalizado, sendo atendido pelas empresas Comgás, Gás Brasiliano e Gás Natural Fenosa. Em termos de rede de gasodutos, conta com uma extensa rede que traz o gás natural da Bolívia e da Bacia Santos para o consumo local, além de transportá-lo para o Sul do país, para Minas Gerais e Rio de Janeiro, em um total de 18.694 mil quilômetros de rede de gasodutos que atende a 143 cidades, como mostra a Figura 1. 


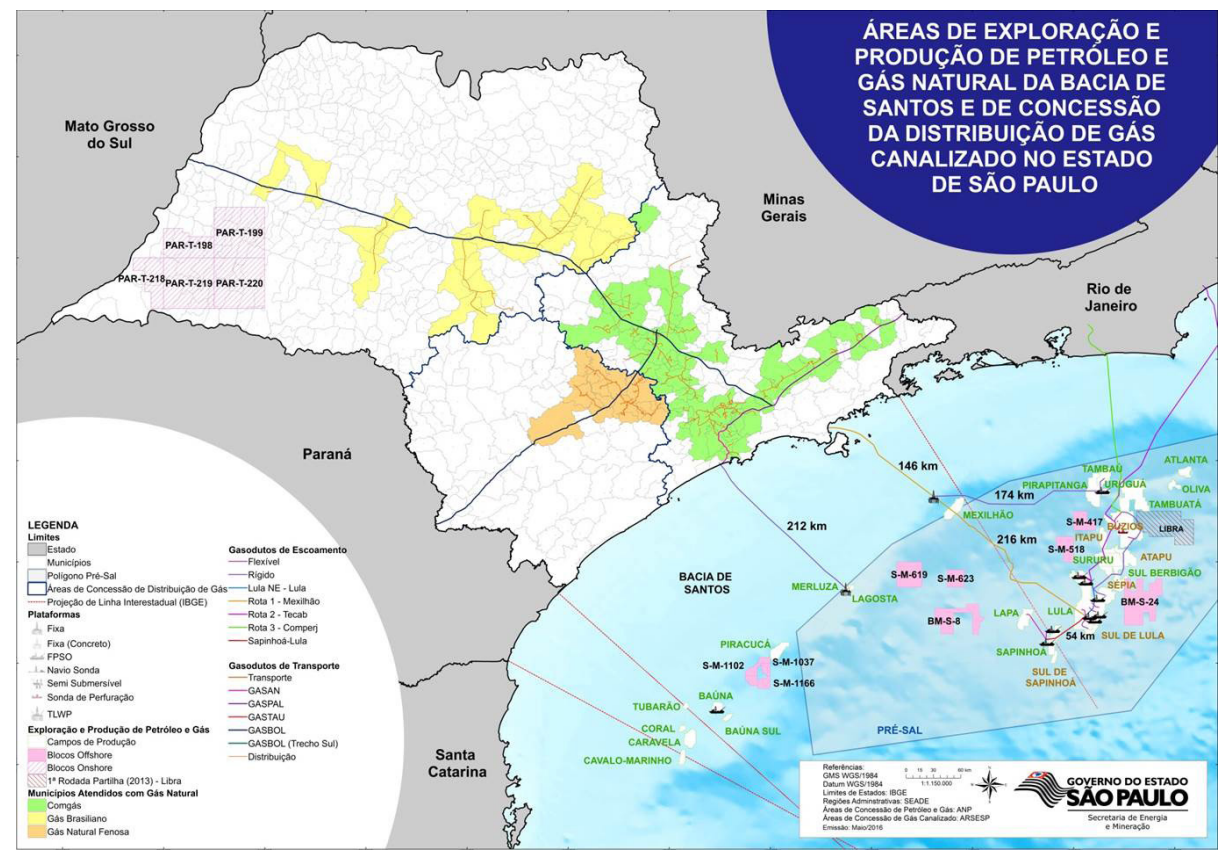

FIGURA 1 - Áreas de concessão de distribuição do gás canalizado

Fonte: Agência Reguladora de Saneamento e Energia do Estado de São Paulo (2017).

\section{Contexto histórico}

A Arsesp é vinculada à Secretaria de Energia e Mineração do Estado de São Paulo, criada pela Lei Complementar n. 1.025, de 7 de dezembro de 2007, e regulamentada pelo Decreto n. 52.455, de 7 de dezembro de 2007, com o objetivo de regular, controlar e fiscalizar os serviços de gás canalizado e de saneamento básico de titularidade estadual, bem como os serviços e as atividades de energia elétrica, de competência da União, ou de saneamento básico, de competência municipal, delegados ao estado de São Paulo pelos órgãos competentes.

\section{Beneficiários}

- Sociedade: usuários dos serviços de concessão de gás canalizado, de saneamento básico e de energia elétrica do estado de São Paulo.

- Concessionárias: três de gás canalizado, três de saneamento básico e 14 distribuidoras de energia elétrica. 


\section{ENTENDIMENTO DO PROBLEMA}

Em entrevistas presenciais com especialistas-chave, responsáveis pela análise técnica no processo de análise das demandas da área do gás canalizado, observou-se que os assuntos são diversos e com distintos impactos e prioridades, e o resultado do atendimento das demandas permite uma ampla gama de benefícios socioeconômicos e ambientais, destacando-se:

- O sistema de distribuição de gás caracteriza-se como infraestrutura para a implantação de novas empresas.

- O uso do gás natural permite maior eficiência energética, garantindo maior competitividade às indústrias que dele se utilizam.

- Possibilita, ainda, a agregação de usinas com indústrias usuárias de vapor d'agua em cogeração, permitindo o aumento de eficiência de ambos os negócios.

- A construção de gasodutos, por si só, gera expectativas positivas da classe empresarial e política, bem como da população em geral, dos municípios localizados na área de influência do empreendimento, com reflexos no aumento da oferta de postos de trabalho.
- Outras formas de uso do gás como fonte energética, com ênfase para o uso residencial e automotivo, são afetadas de forma positiva.

- Melhoria da qualidade do ar em função da redução de emissões de poluentes, devido à substituição pelo gás natural de combustíveis como óleo diesel, gasolina e lenha.

Avançando nas pesquisas, identificou-se que, por causa da ausência de critério objetivo, os processos administrativos tendem a ser analisados de forma mais burocrática, dificultando a agilidade de respostas e flexibilidade de adaptação às mudanças do ambiente externo.

Embora o processo de análise esteja aberto à participação dos agentes impactados, a ausência de critério objetivo faz com que os diversos agentes tenham limitações no acesso às informações disponíveis.

Nesse sentido, Hobbs (1998, p. 20) enfatiza a importância de considerar o "comportamento pessoal no processo da contratação e na especificidade dos ativos necessários para consecução do contrato", englobando a racionalidade limitada, que é caracterizada pela restrição física das pessoas de considerarem todas as alternativas para a tomada de decisão e pelo 
oportunismo, pois as pessoas tendem a explorar uma situação em seu exclusivo benefício.

O oportunismo pode ser identificado em possíveis privilégios no relacionamento com a agência que alguns agentes podem a vir a obter em função da assimetria de informações.

Tendo em vista a necessidade de melhoria no atendimento das demandas da sociedade, eliminando oportunismo e eventuais privilégios no relacionamento com a agência, é necessária uma proposta de mudança visando à inovação.

\section{DIAGNÓSTICO DO PROBLEMA}

A Arsesp é uma autarquia em regime especial que possui maior autonomia administrativa se comparada à autarquia comum. Segundo Aragão (2013), as agências reguladoras foram classificadas como autarquias em regime especial porque houve a necessidade de autonomia e agilidade no exercício de suas funções.

$\mathrm{O}$ artigo $1^{\circ}$, parágrafo único, da Lei Complementar n. 1.025, de 7 de dezembro de 2007, lei de criação da agência, dispõe o seguinte: "O regime jurídico da ARSESP caracteriza-se por independên- cia decisória, autonomia administrativa, orçamentária e financeira, mandato fixo e estabilidade de seus diretores e demais condições que tornem efetiva sua autonomia no âmbito da Administração Pública”.

Diante disso, consolidou-se o entendimento de que o problema seria:

- Como dar maior agilidade ao exercício de suas funções, particularmente no que concerne à análise dos processos das diversas demandas da sociedade, de modo a manter a autonomia da agência?

Atualmente, o processo de análise acontece em ordem cronológica e de priorização subjetiva do gestor responsável. Os processos são recepcionados pela área de Protocolo da Agência que recebe, formalmente, os documentos contendo as demandas de diversos setores da sociedade e de extensa abrangência de assuntos.

Após protocolização da demanda, o processo é distribuído à área técnica que, por sua vez, se encarrega do tratamento até a divulgação do resultado do atendimento da demanda, conforme demonstrado na Figura 2. 
PLANO DIRETOR DE GESTÃO DA INOVAÇÃO EM UMA AGÊNCIA REGULADORA DO ESTADO DE SÃO PAULO
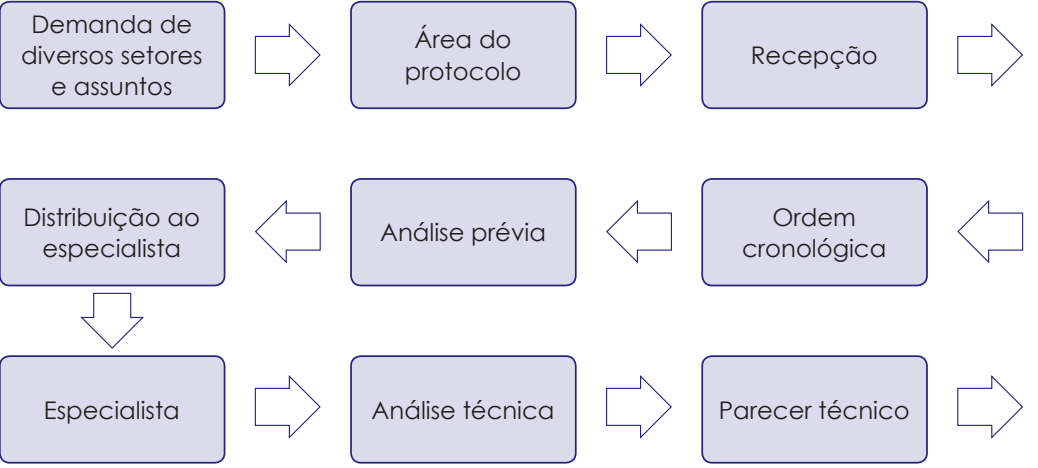

Gestor da área técnica responsável

FigURA 2 - Fluxograma do processo de análise das demandas Fonte: Elaborada pelos autores.

\section{PROPOSTA DE MUDANÇA}

\section{Preparando uma organização inovadora}

Pisano (2016) enfatiza que, apesar dos pesados investimentos para gerir tempo e dinheiro, o processo de inovação ainda é algo bem frustrante para muitas empresas. Iniciativas originais falham frequentemente. E boa parte das organizações que conseguem trazer novidades com sucesso tem dificuldade de manter o desempenho.

Por que é tão difícil cultivar e manter a capacidade de inovação? As razões são muito mais profundas do que falhas de execução, como muitos costumam dizer. O problema está enraizado na falta de estratégia. Entretanto, Tidd, Bessant e Pavitt (2008) afirmam que, independentemente da ideia inovado- ra, é fundamental ter um ambiente favorável para o desenvolvimento do projeto.

$\mathrm{O}$ alto comprometimento é uma tarefa que se espera de todos os envolvidos no processo de inovação, por meio de uma transcrição dos pensamentos em algo palpável, seja ela pela busca de mecanismos que demonstram e reforçam o senso de envolvimento da gestão, compromisso, entusiasmo e apoio.

A aceitação do risco inerente também é mais um ponto a se considerar, a inovação é incerta, e, possivelmente, haverá fracassos, e isso não deve ser um ponto de desmotivação, muito pelo contrário, com os erros cometidos adquirem-se mais experiências para que no futuro possam ser evitados.

Pisano (2016) reforça a importância do alto comprometimento ao enfatizar que o processo de criar algo novo atravessa todas as funções. Os profissionais seniores 
são os mais indicados para orquestrar um sistema tão complexo.

Eles devem assumir a principal responsabilidade sobre os processos, as estruturas, os talentos e os comportamentos que moldam como a organização busca por oportunidades de inovação, além de sintetizar ideias em conceitos e projetos de produtos e escolher como atuar.
Além da liderança e do comprometimento, esse plano considera que o executivo líder e demais indivíduos-chave, designados e apresentados hierarquicamente no organograma (Figura 3), deverão ser sempre agentes de mudança ativos, fundamentais para defender e oferecer força e entusiasmo para levar a inovação adiante.

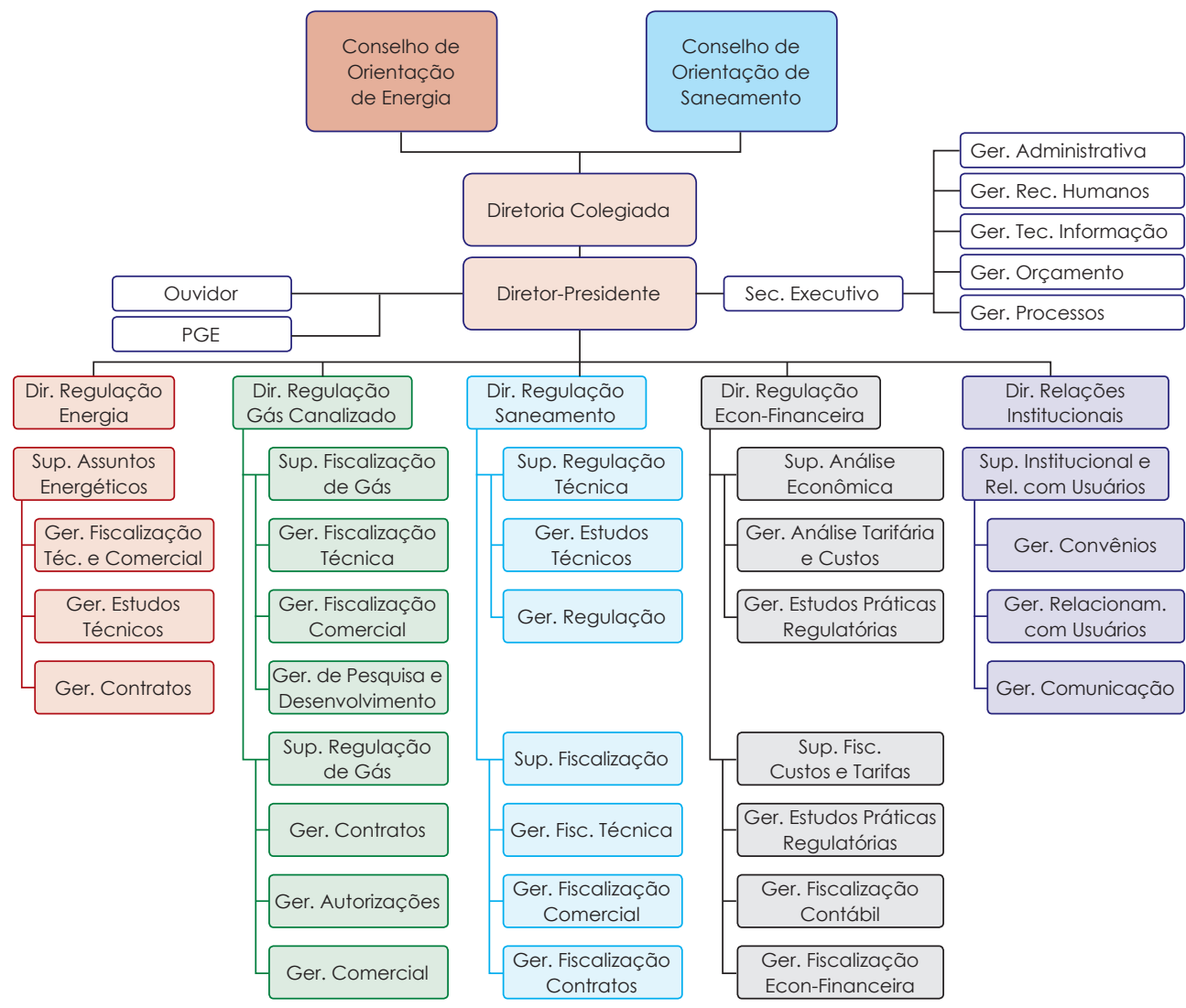

FigurA 3 - Organograma da Arsesp

Fonte: Agência Reguladora de Saneamento e Energia do Estado de São Paulo (2018). 
Indivíduos-chave da equipe de gestão de inovação

Executivo líder: diretora de gás canalizado subordinada ao diretor-presidente; gestor técnico: gerente técnico de informação subordinado à secretaria executiva, subordinada ao diretor-presidente inovador de negócios; superintendente de regulação do gás: subordinada à diretora de gás canalizado.

Cabe ressaltar que os indivíduos-chave liderarão equipes que, para terem um bom desempenho, deverão considerar importantes aspectos citados por Tidd, Bessant e Pavitt (2008):

- Objetivos e tarefas claramente definidos.

- Mecanismos de coleta e distribuição de informações (internet, intranet, e-mails, campanhas de divulgação etc.), de modo a permitir um constante crescimento no reconhecimento da partilha eficaz e da comunicação de informações valiosas.

- Liderança de equipe eficaz.

- Bom equilíbrio entre papéis de equipe e estilo comportamental individual.

- Mecanismos eficazes de resolução de conflito dentro do grupo.

- Conexão contínua com a organização externa.
Com o objetivo de um melhor atendimento aos processos de análise das demandas oriundas de diversas áreas da sociedade, propõe-se a implantação do PDGI baseado nos pilares relacionados a seguir. Porém, três deles são fundamentais para a condução de uma organização.

$\mathrm{O}$ primeiro pilar diz respeito à visão da empresa, que, para Oliveira (2005), está associada a um cenário ou horizonte desejado pela empresa para sua atuação e está direcionado para o futuro.

O segundo é a missão. Segundo Drucker (2011), uma empresa não é definida por seu nome, estatuto ou produto que faz. É definida por sua missão. É necessário que seja uma definição clara que demonstre a razão de existir da organização.

E, por fim, o terceiro, que está relacionado aos valores da empresa. De acordo com Barret (2000), em uma organização os valores "dizem" e os comportamentos "fazem", de modo a definir os princípios que guiam a vida da organização.

Assim, são apresentados, a seguir, a visão, a missão e os valores da Arsesp:

- Visão: Ser a agência para o bem-estar da população do estado de São Paulo.

- Missão: Regular e fiscalizar os serviços de energia elétrica, gás canalizado e sa- 
neamento básico prestados pelas concessionárias.

- Valores: Respeito aos contratos de concessão, respeito do direito administrativo e cultura da inovação.

- Políticas: Fazer cumprir os contratos de concessão e assegurar o equilíbrio econômico-financeiro dos contratos de concessão.

- Diretrizes: Fiscalização do cumprimento dos contratos de concessão, controle e arbitragem de conflitos, fomentar a competitividade das concessionárias e controlar tarifas dos serviços.

\section{Mapa estratégico}

O mapa estratégico sintetiza e representa visualmente os direcionamentos estratégicos estabelecidos pela empresa Arsesp para o horizonte 2021, traduzidos na missão, na visão e em um conjunto abrangente de diretrizes e objetivos norteadores do desempenho institucional. Esse framework visa facilitar a comunicação e a gestão da inovação na empresa Arsesp.

Notam-se, também, as perspectivas de metas e indicadores, e, ainda, os fatores fundamentais que farão o eixo central na integração da Arsesp com o mercado, conforme a Figura 4.

\section{DETALHAMENTO DO PDGI}

Segundo Tidd, Bessant e Pavitt (2008), a inovação é uma ação associada à sobrevivência e ao crescimento da empresa, em que o processo de inovar envolve: procurar (analisar o cenário), selecionar (processo de decidir a melhor opção) e implementar a estratégia. Essa ação necessita de conhecimento para inovar, execução do projeto que exige capacidade para resolver problemas, lançamento da inovação, sustentabilidade e aprendizado com a progressão do projeto e melhoraria constante. As inovações variam em proporção, natureza, novidade e outros.

Ao pensarem em inovação, Tidd, Bessant e Pavitt (2008) citam dois modelos:

- "Fazendo o que se sabe, mas melhor": trata-se de uma condição instável que opera de acordo com as rotinas.

- No projeto, adotou-se o modelo de inovação "fazer de um jeito diferente", no qual a agência irá operar de um modo diferente por causa das mudanças tecnológicas e mercadológicas e do gerenciamento nas condições de incerteza. 
PLANO DIRETOR DE GESTÃO DA INOVAÇÃO EM

UMA AGÊNCIA REGULADORA DO ESTADO DE SÃO PAULO
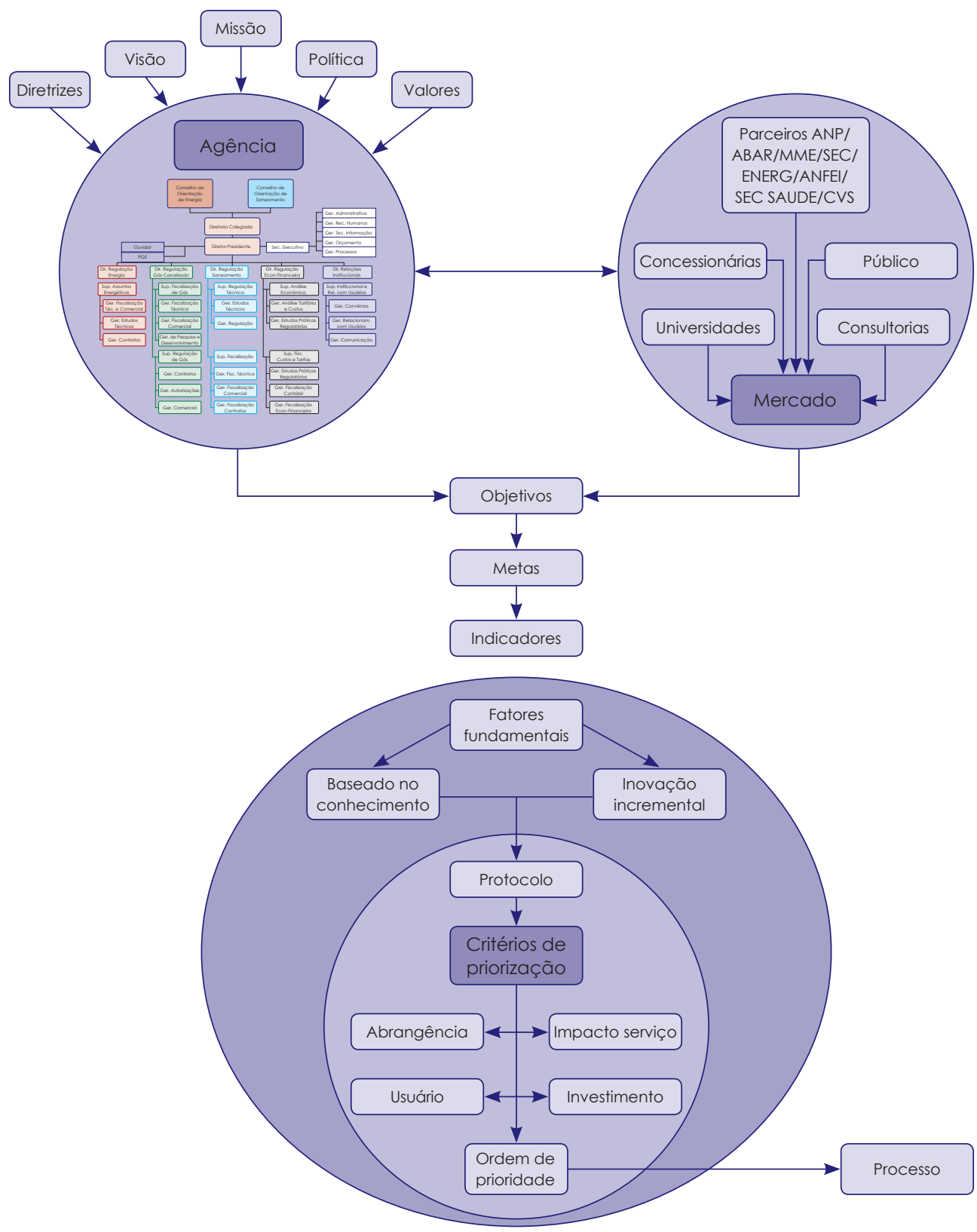

Figura 4 - Framework do PDGI da Arsesp

Fonte: Elaborada pelos autores. 
A seguir, são relacionados os principais componentes do fluxograma apresentado na Figura 2, abrangendo as principais variáveis e respectivas inter-relações que irão interferir no processo de inovação da agência.

\section{Relação da Arsesp e os agentes do mercado}

Segundo Lovelock, Wirtz e Hemzo Lovelock (2011), alguns fatores vêm remodelando o mercado, de modo a envolver a demanda, a oferta e até mesmo o estilo de vida dos consumidores. As transformações econômicas foram geradas por essas forças, sendo algumas delas tendências de negócios, avanços em tecnologia da informação e mudanças sociais.

O mercado tem função primordial para a motivação da Arsesp na criação e posterior execução do PDGI. Nesse sentido, Duncan (1972, p. 314) mostra que o ambiente externo das organizações "consiste em todos os fatores físicos e sociais relevantes que estão fora dos limites da organização e que são levados diretamente em consideração durante a tomada de decisão pelos indivíduos no sistema”.

Drucker (2002), por sua vez, afirma que a maior mudança na cultura corpora- tiva pode ser o crescimento acelerado de relacionamentos baseados não em propriedade, mas em parceria.

Na primeira perspectiva, o framework apresenta a relação da Arsesp e os agentes atuantes do mercado, no qual a agência encontra-se inserida. De acordo com Drucker (2002), a maior mudança na cultura corporativa pode ser o crescimento acelerado de relacionamentos baseados não em propriedade, mas em parceria.

Entre os agentes do mercado, alguns são parceiros da Arsesp:

- Secretaria de Energia e Mineração do Estado de São Paulo, que coordena as ações para o suprimento, a universalização, a confiabilidade e a qualidade de insumos energéticos, visando ao desenvolvimento econômico sustentável do estado.

- Agência Nacional do Petróleo, Gás Natural e Biocombustíveis (ANP), órgão regulador das atividades que integram as indústrias de petróleo e gás natural e de biocombustíveis.

- Empresas concessionárias prestadoras dos serviços de concessão do estado de São Paulo: 14 empresas de distribuição de energia elétrica, 3 de distribuição de gás canalizado e 290 municí- 
pios conveniados para os serviços prestados de saneamento básico, distribuídos em três empresas.

- Universidades conveniadas que participam da prestação de serviços e executam estudos técnicos e pesquisas.

- Consultorias de prestação de serviços específicos no desenvolvimento de tecnologia da informação, estudo econômico-financeiro e estudos técnicos.

O setor público é considerado um agente do mercado, representado pela sociedade civil e pelos usuários dos serviços de concessão.

\section{Fatores fundamentais para a inovação incremental}

Tidd, Bessant e Pavitt (2008) apresentam quatro formas de "inovação" (os "4 Ps" da inovação):

- Inovação de produto: mudanças nas coisas (produtos/serviços) que uma empresa oferece.

- Inovação de processo: mudanças na forma como os produtos/serviços são criados e entregues.

- Inovação de posição: mudanças no contexto em que produtos/serviços são introduzidos.
- Inovação de paradigma: mudanças nos modelos mentais subjacentes que orientam o que a empresa faz.

Esse projeto da Arsesp abrange a inovação de processos e de paradigma, na medida em que será alterado o processo de recebimento e tratamento de demandas, e haverá a readequação das formas de priorização das demandas para análise.

Tidd, Bessant e Pavitt (2008) enfatizam o papel do conhecimento para a inovação, criando novas possibilidades por meio da combinação de diferentes conjuntos de conhecimentos. Estes podem vir na forma de conhecimento sobre o que é tecnicamente possível ou de que configuração pode responder a uma necessidade articulada ou latente.

Tal conhecimento pode já existir, baseado em algo que já foi visto ou experimentado antes, ou pode estar explícito em sua forma, codificado de modo que outros possam acessá-lo, discuti-lo, transferi-lo etc. - ou pode existir de modo tácito: conhecido, mas sem formulação.

No contexto do projeto, o conhecimento refere-se às diversas demandas dos setores da sociedade à Arsesp. Esse conhecimento é fundamental para a definição de critérios de priorização. Pode-se considerar 
a estimativa na ordem de 1.500 processos para análise/ano, que, atualmente, não possuem um critério definido de priorização.

Estudos acerca do desenvolvimento do processo incremental, tal como o de Hollander (1965), sugerem que os ganhos cumulativos de eficiência são muito maiores em longo prazo do que aqueles obtidos com as mudanças radicais ocasionais.

Experiências mais recentes com a aplicabilidade da mentalidade "enxuta" de gestão, verificadas no setor de serviços e, de forma crescente, entre empresas, bem como dentro delas, enfatizam o grande potencial desse tipo de inovação contínua. $\mathrm{O}$ framework apresenta, na segunda perspectiva, a relação dos fatores fundamentais para os critérios de priorização, baseado no conhecimento e na inovação incremental.

\section{PROPOSTA DE SOLUÇÃO}

\section{Inovando o atendimento de demandas com critérios de priorização}

A proposta do projeto é que, a partir dos critérios de priorização, as demandas sejam atendidas de forma objetiva, conforme ordem de prioridade definida por um cri- tério preestabelecido, visando ao interesse público. Esse critério engloba o desenvolvimento econômico e a sustentabilidade, o desenvolvimento social e o desenvolvimento urbano e regional.

Que tipos de inovação podem permitir criar e captar valor para a empresa e quais são os recursos para isso? Certamente, novidades tecnológicas podem gerar valor econômico e vantagem competitiva.

A priorização das demandas, apresentada no projeto, será feita com a utilização da tecnologia, visando à automação dos processos. O desenvolvimento da tecnologia de automação dos processos se dará com a contratação de agentes do mercado, por meio de consultoria especializada ou convênio com fundações das universidades.

Para Tigre (2006), a tecnologia está cada vez mais presente no mundo de hoje, alterando-se ao longo dos anos e sendo a responsável pela globalização que interliga o mundo inteiro. A tecnologia auxilia as transformações econômicas, sociais e institucionais, e necessita de motivação econômica, regimes e condições para se desenvolver e não se difundir.

É um fator dependente que, desacompanhado de uma adaptação, não é suficiente para ajudar a competitividade da organi- 
zação. A principal motivação para se adotar a tecnologia nas empresas é a necessidade de uma melhor utilização de seus recursos financeiros, investidos em máquinas e manutenção de sistemas empresariais.

Tigre (2006) argumenta que os itens tecnológicos vêm fazendo parte cada vez mais da vida das pessoas, mudando seus costumes de maneira progressiva e as tornando cada vez mais dependentes de seu uso. As tecnologias trazem facilidade, conforto e praticidade, além das inovações que consequentemente necessitam de uma habilidade para praticá-las. Há uma grande diferença entre tecnologia e técnicas: a tecnologia abrange o conhecimento sobre técnicas, enquanto estas abrangem aplicações desse conhecimento em processos, produtos e métodos organizacionais.

Essa proposta de atendimento de demandas com base em critérios de priorização será realizada a partir da plataforma da entrada dos processos na área de protocolo, e o usuário terá acesso ao sistema por meio da criação de login e senha. Nesse sistema, serão solicitadas informações necessárias para a classificação da ordem de prioridade, conforme os critérios de priorização.

Oliveira (2006, p. 8) define processo como um "conjunto estruturado de ativi- dades sequenciais que apresentam relação lógica entre si, com a finalidade de atender e, preferencialmente, suplantar as necessidades e as expectativas dos clientes externos e internos da empresa".

Neste relato sobre a Arsesp, os clientes externos estão divididos em dois grupos. Em um grupo se concentram as empresas a ela ligadas, como energia elétrica, gás canalizado e saneamento básico prestados pelas concessionárias. Mas, nesse caso específico, são agrupadas as empresas de distribuição de gás canalizado. O outro cliente é a comunidade do estado de São Paulo.

Quando se redesenham os processos e se adicionam ou se eliminam etapas, é necessária a elaboração de novos procedimentos. Neste relato, foi necessária a introdução de critérios de priorização a fim de possibilitar melhor análise técnica de um projeto submetido à agência.

Os critérios de priorização atenderão às seguintes abordagens: impacto para o usuário, abrangência, impacto do serviço e investimento.

Dessa maneira, os critérios de priorização serão avaliados com parâmetros qualitativos, com notas atribuídas de 1 a 3, conforme mostra a Tabela 1 . 
TABELA 1 - Classificação qualitativa

\begin{tabular}{cc}
\hline Impacto para o usuário & Número de usuários \\
\hline Nota 1 & De 1 a 5 \\
\hline Nota 2 & De 6 a 20 \\
\hline Nota 3 & $>20$ \\
\hline Abrangência & Usuários atendidos \\
\hline Nota 1 & 01 - 10.000 \\
\hline Nota 2 & $10.001-100.000$ \\
\hline Nota 3 & $>$ ou $=100.001$ \\
\hline Impacto do serviço & Volume em m $^{3} /$ mês \\
\hline Nota 1 & De 0,00 a $2.000,00$ \\
\hline Nota 2 & De $2.001,00$ a 50.000 \\
\hline Nota 3 & $>$ ou $=50.001$ \\
\hline Investimento & Em milhões $/$ projeto \\
\hline Nota 1 & Até R $\$ 2.000 .000$ \\
\hline Nota 2 & De R $\$ 2.000 .001$ a $R \$ 10.000 .000$ \\
\hline Nota 3 & ou $\$ 10.000 .001$ \\
\hline
\end{tabular}

Fonte: Elaborada pelos autores.

Após a atribuição das notas, a definição da ordem de prioridade será dada conforme a seguinte fórmula:

$\mathrm{OP}=($ Nota de impacto para o usuário $\mathrm{x}$ Peso 4) + (Nota da abrangência x Peso 3$)$ + (Nota do impacto do serviço x Peso 2) + (Nota do investimento x Peso 1)

onde:

- O impacto para o usuário recebe o peso 4 e tem a finalidade de classificar o nú- mero de usuários que sofreram impactos dos serviços (pessoa física ou jurídica).

- A abrangência recebe o peso 3 e tem a finalidade de classificar o número de usuários atendidos pelos serviços de concessão (pessoa física ou jurídica).

- O impacto do serviço recebe o peso 2 e tem a finalidade de classificar o volume do consumo dos usuários.

- O investimento recebe o peso 1 e tem a finalidade de classificar o montante em reais a ser investido em projetos. 
Considerando o resultado da fórmula, a ordem de prioridade obedecerá à classificação da Tabela 2.

TABELA 2 - Classificação de prioridade

\begin{tabular}{cc}
\hline Ordem de priorização & Escala \\
\hline Essencial & $>$ ou $=26$ \\
\hline Relevante & $>$ ou $=21$ \\
\hline Moderada & $>$ ou $=10$
\end{tabular}

Fonte: Elaborada pelos autores (2018).

Para efeito de padronização dos processos, os seguintes conceitos serão utilizados:

- Essencial: representa os processos mais significativos que deverão ter prioridade sobre os demais no atendimento da demanda.

- Relevante: representa os processos importantes que deverão ter prioridade média sobre os demais no atendimento da demanda.

- Moderado: representa os processos de menor importância que deverão ter prioridade baixa sobre os demais no atendimento da demanda.

\section{Critério de desempate}

No caso de empate resultante da fórmula, a ordem de priorização dos processos seguirá a seguinte hierarquia:
1) Maior nota obtida na classificação qualitativa do impacto para o usuário.

2) Maior nota obtida na classificação qualitativa da abrangência.

3) Maior nota obtida na classificação qualitativa do impacto do serviço.

4) Maior nota obtida na classificação qualitativa do investimento.

\section{Exemplo de demanda priorizada pelo critério}

Uma concessionária de gás canalizado, em determinada região industrial, solicita a análise de um projeto de extensão de rede visando ao atendimento a três indústrias do setor alimentício, e, consequentemente, estenderá o fornecimento de gás a uma população de 200 mil habitantes.

A classificação qualitativa apresenta os seguintes números:

- Impacto para o usuário: três empresas.

- Abrangência: 200 mil novos usuários ligados à rede.

- Impacto do serviço: consumo estimado de gás $3.000 .000 \mathrm{~m}^{3}$.

- Investimento: estimado em R\$ 10.000.000,00. 
Nota do impacto para o usuário $=1$

Nota da abrangência $=3$

Nota do impacto do serviço $=3$

Nota do investimento $=3$

$O P=(1 \times 4)+(3 \times 3)+(3 \times 2)+(2 \times 1)$

$\rightarrow 21$

A ordem de priorização do projeto é relevante, e o processo terá prioridade média sobre os demais processos no atendimento da demanda.

\section{GANHOS COM A SOLUÇÃO}

\section{Metas e indicadores}

Em perspectiva, o framework ainda apresenta as metas e os indicadores. As metas serão definidas em linha com o Plano Plurianual da Secretaria de Gestão do Governo do Estado de São Paulo. Após um determinado período, um ano de avaliação do realizado, observar-se-á a quantidade de processos atendidos, e, por conseguinte, as metas serão reavaliadas.

Os indicadores serão definidos com base nos critérios de priorização, como:

- Quantidade de processos priorizados pelo critério.
- Tempo gasto nos processos priorizados pelo critério.

- Número de reclamações para cada dez mil ligações (usuários ligados na rede) atendidas pelo critério e apuradas no Serviço de Atendimento ao Usuário etc.

\section{CONSIDERAÇÕES FINAIS}

$\mathrm{Na}$ fase de execução do PDGI, a estrutura organizacional da ARSESP, especificamente a área da diretoria do gás canalizado, assumirá o papel do agente que promoverá a construção da organização inovadora, consciente do fato que enfrentará grandes desafios, na medida em que as mudanças culturais não acontecem com rapidez ou como resultado de iniciativas individuais.

Tidd, Bessant e Pavitt (2008) ressaltam a importância de implantar o desenvolvimento sistemático de estruturas organizacionais, políticas de comunicação e procedimentos, sistema de recompensa e reconhecimento, política de treinamento, entre outros.

É oportuno, em uma organização com cultura inovadora, o empreendedorismo interno que oferece apoio e estímulo aos indivíduos com boas ideias. Inicialmente, o projeto aqui proposto, critérios 
de priorização e ordem de prioridade, será estruturado em planilha Excel, desenvolvida pela área da diretoria do gás canalizado e utilizada pela área de protocolo na recepção dos processos específicos dessa área.

Após a fase de avaliação do projeto e eventuais ajustes na qualificação e abrangência dos critérios de priorização, o desenvolvimento da tecnologia de automação dos processos será implementado. Mas como garantir a continuidade do sucesso da inovação? Será necessário considerar não somente o acerto e o erro, mas, sobretudo, refletir e aprender com os erros e acertos, mantendo uma memória organizacional.

Nesse sentido, serão criados mecanismos de aprendizagem para lidar com novas demandas dos agentes de mercado, que exigirão novos critérios de priorização, novos pontos de abordagens e, consequentemente, nova ordem de prioridade.

$\mathrm{Na}$ fase final, a visão do projeto de inovação e a atmosfera inovadora serão compartilhadas com as demais diretorias saneamento básico, energia elétrica, econômico-financeiro e relações institucionais - sob o patrocínio e alto envolvimento da diretoria colegiada.

Dessa forma, a Arsesp, efetivamente, será transformada em um agente de mu- danças ativo, com um modelo de gestão de inovação que permitirá que ela cumpra sua missão e seus valores dentro da visão que foi concebida: "Ser agência para o bem-estar da população do estado de São Paulo”.

\section{MASTER PLAN FOR INNOVATION IN A REGULATORY AGENCY OF THE STATE OF SÃO PAULO}

\section{ABSTRACT}

The present study presents the Management Plan for Innovation (PDGI), which will be implemented in a regulatory agency of the State of São Paulo, aiming to transform it into an innovative local authority, which will improve the service to the demands of different areas of society. The Master Plan for Innovation Management establishes the main guidelines for the activities to be carried out at the São Paulo State Sanitation and Energy Regulatory Agency (Arsesp), during the period from 2018 to 2021. This document describes the premises that elaboration of the strategic map, visually represented by the framework, which synthesizes and visually represents the strategic directions that will be established by Arsesp, translated by mission, vision and covering guidelines and objectives guiding institutional performance. Through the innovation management model will be presented, in the form of process innovation, the criterion of prioritization 
of the analysis of the demands. The proposal foresees that initially the Master Plan for Innovation Management be executed in the area of the piped gas directorate, serving as a basis for preparation for the formation of an innovative atmosphere that will later be shared for the directorates of basic sanitation and electric energy, under the sponsorship and high involvement of the collegiate board.

\section{KEYWORDS}

Innovation management. Master plan. Regulatory agency. Criteria for prioritization.

\section{REFERÊNCIAS}

AGÊNCIA REGULADORA DE SANEAMENTO E ENERGIA DO ESTADO DE SÃO PAULO. Áreas de concessão de distribuição do gás canalizado. 2017. Disponível em: http://www.arsesp.sp.gov. br/Documentosgerais/MAPAS-05-2017GAS-CANALIZADO.pdf. Acesso em: $1^{\circ}$ maio 2017.

AGÊNCIA REGULADORA DE SANEAMENTO E ENERGIA DO ESTADO DE SÃO PAULO. Estrutura Organizacional. 2018. Disponível em: http://www.arsesp. sp.gov.br/SiteAssets/SitePages/organograma/organograma_final2-01.jpg. Acesso em: $1^{\circ}$ jul. 2018.
ARAGÃO, A. S. de. Agências reguladoras e a evolução do direito administrativo econômico. Rio de Janeiro: Forense, 2013.

BARRET, R. Libertando a alma da empresa: como transformar a organização numa entidade viva. São Paulo: Cultrix, 2000.

DOWNEY, H. K.; HELLRIEGEL, D.; SLOCUM, J. W. Environmental uncertainty: the construct and its application. Administrative Science Quarterly, v. 20, n. 4, Dec. 1975.

DRUCKER, P. F. A administração em tempos de crise. 3. ed. São Paulo: Pioneira, 2002.

DRUCKER, P. F. Drucker em 33 lições: as melhores aulas do homem que inventou a administração. São Paulo: Saraiva, 2011.

DUNCAN, R. B. Characteristics of organizational environments and perceived environmental uncertainty. Administrative Science Quarterly, v. 17 n. 3, Sept. 1972.

GALBRAITH, J. R. Designing complex organizations. Addison-Wesley, 1973

HOBBS, J. E. A transaction cost analysis of quality, traceability and animal welfare issues in UK beef retailing. British Food Journal, v. 98, n. 6, p. 20-26, 1998.

HOLLANDER, S. The sources of increased efficiently: a study of DuPont rayon plants. Cambridge, MA: MIT Press, 1965. 
LAWRENCE, P. R.; LORSCH, J. W. Organization and environment managing differentiation and integration. Boston: Harvard University Press, 1967.

LOVELOCK, C.; WIRTZ, J.; HEMZO, M. A. Marketing de serviços: pessoas, tecnologia e estratégia. São Paulo: Pearson Prentice Hall, 2011.

MARCONDES, R. C. et al. Metodologia para elaboração de trabalhos práticos e aplicados: administração e contabilidade. São Paulo: Editora Mackenzie, 2017. E-book. (Conexão Inicial).

OLIVEIRA, D. de P. R. de. Planejamento estratégico, conceitos metodologia práticas. 22. ed. São Paulo: Atlas, 2005.

OLIVEIRA, D. de P. R. de. Administração de processos. São Paulo: Atlas, 2006.

PISANO, G. P. Você precisa de uma estratégia de inovação. Harvard Business Review, fev. 2016. Disponível em: https:// hbrbr.uol.com.br/inovacao/page/4/. Acesso em: 20 maio 2019.

TIDD, J.; BESSANT, J.; PAVITT, K. Gestão da inovação. Porto Alegre: Bookman, 2008.

TIGRE, P. B. Gestão da inovação: a economia da tecnologia do Brasil. Rio de Janeiro: Elsevier, 2006. 